\title{
Video View to Followers Ratio Instagram pada Top 10 Brand Terkenal di Dunia
}

\author{
Anastasia Diana Armida Selivan
}

Dianaselivan47@gmail.com

\begin{abstract}
Abstrak
Era digital menjadikan komunikasi memasuki babak baru. Teknologi baru yang semakin maju, internet semakin mudah diakses, aplikasi semakin banyak dan media sosial untuk berkomunikasi juga semakin beragam. Setiap orang dengan akses internet (komputer, laptop, smartphone ataupun perangkat sejenisnya) bisa dengan mudah menggunakannya. Disebut sebagai new wave technology, merupakan sebuah teknologi yang menghubungkan antar individu dan kelompok. New wave technology didukung oleh perangkat informasi yang semakin canggih sehingga memunculkan gelombang revolusi teknologi baru. Kekuatan utama dari new wave technology ada pada perangkat informasi baru seperti komputer, handphone, serta akses internet murah. Seperti yang telah diungkapkan diatas, salah satu media yang disebut new wave technology ini adalah internet. Instagram dirasakan memiliki kekuatan ataupun pengaruh dalam industri, sehingga menimbulkan kualitas akun yang menentukan strata maupun kredibilitas pemilik akun. Kredibilitas akun instagram merupakan suatu hal yang cukup penting untuk berbagai kepentingan. Kredibilitas sebuah akun instagram dapat diukur dari tingkat performa yang dihasilkan secara matematis. Dalam mengukur performa diperlukan skala pengukuran yang tertuang ke dalam rasio.
\end{abstract}

\section{PENDAHULUAN}

Era digital menjadikan komunikasi memasuki babak baru. Teknologi baru yang semakin maju, internet semakin mudah diakses, aplikasi semakin banyak dan media sosial untuk berkomunikasi juga semakin beragam. Setiap orang dengan akses internet (komputer, laptop, smartphone ataupun perangkat sejenisnya) bisa dengan mudah menggunakannya. Disebut sebagai new wave technology, merupakan sebuah teknologi yang menghubungkan antar individu dan kelompok. New wave technology didukung oleh perangkat informasi yang semakin canggih sehingga memunculkan gelombang revolusi teknologi baru. Kekuatan utama dari new wave technology ada pada perangkat informasi baru seperti komputer, handphone, serta akses internet murah. Seperti yang telah diungkapkan diatas, salah satu media yang disebut new wave technology ini adalah internet.

Salah satu layanan yang lahir berkat adanya akses internet ini adalah jejaring sosial. Jejaring sosial seakan memperkuat kedudukan internet new media comonication, dimana jarak seakan tidak lagi terlihat, informasi dan pesan bisa tersampaikan secara global dalam waktu singkat. Dengan kata lain masing masing penemuan media baru diharapkan dapat memperluas beberapa kemampuan dan kecakapan manusia (Nurudin, 2012) . salah satu media sosial yang paling banyak digunakan adalah instagram. Dengan jumlah pengguna yang terus meningkat instgram menjadi suatu peluang terbesar bagi para pebisnis dalam melakukan promosi produk yang hendak diluncurkan. Selain penggunaan yang cukup praktis dan tidak memerlukan biaya yang besar, sehingga instagram dapat dijadikan sebagai strategi marketing dalam hal mempromosikan produk mereka kepada semua orang. Cukup banyak akun-akun brand terkenal yang ada di instagram seperti Dolce and Gabanna, Gucci, Ralp Laurent, gior Gior 
Armani, yvest saint lauren, Prada, Chanel, Versace, Christian Dior, dan louis vuitton ("Top 10 Brand Terkenal di Dunia ").

Penelitian ini menggunakan metode eksploratif kuantitatif, dan akan menghitung menggunakan rasio-rasio yang ada pada instagram. Rasio-rasio tersebut digunakan sebagia alat ukur untuk melakukan analisa pada akun yang ada. Penelitian hanya berfokus menghitung kredibilitas Video View to Followers Ratio Instagram pada Top 10 Brand Terkenal di Dunia, yaitu: Dolce and Gabanna, Gucci, Ralp Laurent, gior Gior Armani, yvest saint lauren, Prada, Chanel, Versace, Christian Dior, dan louis vuitton. Tujuan dari penelitian ini dalah untuk mengetahui kredibilias performa dari akun instagram Top 10 Brand Terkenal di Dunia menggunakan ideo View to Followers Ratio. 


\section{TINJAUAN PUSTAKA}

Komunikasi pemasaran sebagai cara perusahaan dalam menginformasikan, mengajak, dan mengingatkan konsumen baik secara langsung maupun tidak langsung mengenai suatu produk atau brand yang dijualnya. Perkembangan bidang teknologi saat ini terjadi begitu pesat. Melalui perkembangan yang terjadi dari waktu ke waktu menimbulkan maraknya aplikasi aplikasi serta platform media sosial yang bermunculan. Aplikasi yang sangat diminati oleh masyarakat saat ini diantaranya adalah TikTok, Instagram, Twitter, WhatsApp dan yang lain sebagainya. Seiring berjalannya waktu, aplikasi sosial media tersebut dapat menjadi candu bagi kalangan masyarakat. Tidak hanya kalangan remaja yang menggunakan aplikasi sosial media, orang tua bahkan anak-anak juga aktif menggunakan aplikasi sosial media tersebut.

instagram merupakan salah satu new media yang menjadi media sosial yang gemari banyak kalangan pada jaman sekarang. Seperti yang kita ketahui, media sosial instagram merupakan salah satu media sosial yang tren di Indonesia(Saputera dan Tamburian, 2019).

Dari sekian banyak media sosial instagram menjadi salah satu media yang paling banyak penggunanya. Meski fitur-nya tidak selengkap platform sosial media lain, Instagram cukup diminati dan menjadi tempat yang strategis bagi para pebisnis pemula untuk memasarkan produknya. Bahkan saat ini industri yang sudah mapan pun mulai melirik Instagram sebagai media yang efektif untuk mendekatkan dan memasarkan produknya pada pengguna Instagram yang kebanyakan adalah generasi muda. Instagram merupakan salah satu media sosial yang dapat dimafaatkan sebagai media pemasaran lansung. Melalui instagramlah produk barang atau jasa ditawarkan dengan mengupload foto atau video singkat, sehingga bisa menarik para konsumennya.

Instagram dirasakan memiliki kekuatan ataupun pengaruh dalam industri, sehingga menimbulkan kualitas akun yang menentukan strata maupun kredibilitas pemilik akun. Kredibilitas akun instagram merupakan suatu hal yang cukup penting untuk berbagai kepentingan. Kredibilitas sebuah akun instagram dapat diukur dari tingkat performa yang dihasilkan secara matematis. Dalam mengukur performa diperlukan skala pengukuran yang tertuang ke dalam rasio.

\section{METODE PENELITIAN}

Penelitian menggunakan metode ekspolaratif kuantatif untuk mengetahui kredibilitas untuk mengetahui kredibilitas dari performa akun akun instagram Top 10 Brand Terkenal di Dunia. Tujuan dari peneitian ini adalah untuk mengetahui nilai kredibilitas dari performa akun instagram Top 10 Brand Terkenal di Dunia. Langah langkah yang dilakukan pada penelitian ini adalah sebagai berikut:

1. Melakukan Eksplorasi Pada Website Untuk Menentukan Objek yang Akan Dianalisa.

Eksplorasi ini dilakukan pada beberapa halaman website yang menyediakan informasi mengenai objek yang akan di teliti. Setelah ekslorasi selesai dilakukan, sehingga ditemukan nama-nama 10 brand yang terkenal yang akan dijadikan objek analisa. Setelah melakukan eksplorasi pada halaman website, maka langkah selanjutnya yaitu mencari nama akun instagram dari masing-masing brand.

2. menghitung nilai rata rata dari masing masing variabel 
pada langkah ini peneliti menghitung nilai variabel video view to followers. Variabel merupakan sesuatu yang memiliki nilai bervariasi dimana nilai tersebut dapat dijadikan sebagai dasar data yang berbeda, seperti rasio. Skala,

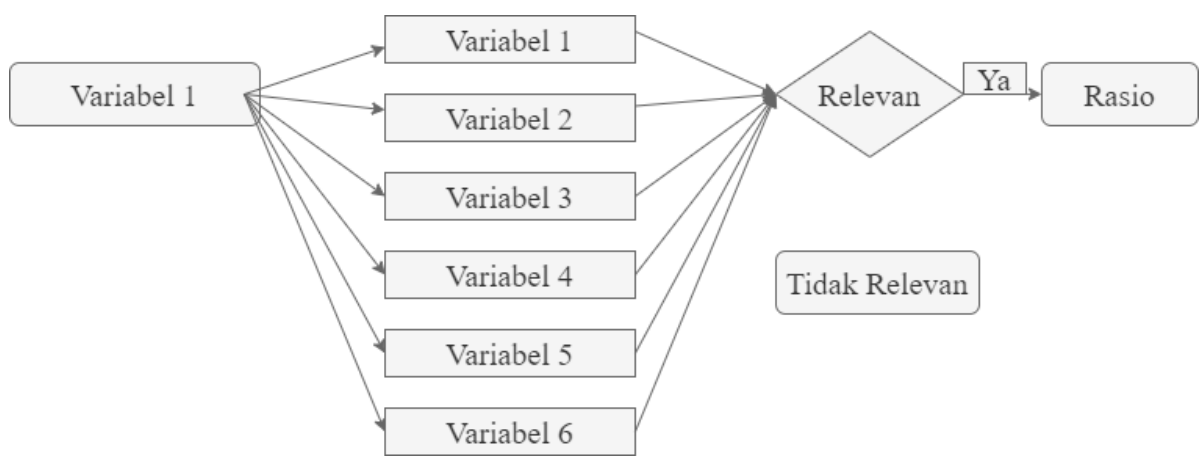

Gambar 1. Analisa nilai rata rata variabel

3. membuat perangkingan

Pada langkah terakhir yang dilakukan pada penelitian ini yaitu menentukan peringkat pada masing-masing rasio yang ada. Pada penentuan peringkat perlu melihat karakteristik dari rasio yang di teliti. Jika karakteristik rasio merupakan rendah, maka objek yang memiliki nilai terendah akan mendapatkan angka 10 dan objek yang memiliki nilai tertinggi akan mendapatkan angka 1. Namun jika rasio memiliki karakteritik tinggi maka objek yang mendapatkan nilai tinggi akan mendapatkan angka 10 dan objek yang mendapatkan nilai terendah akan mendapatkan angka 1. Setelah mendapatkan hasil kredibilitas ratio maka dapat disimpulkan objek yang mana mendapatkan peringkat 1 sampai dengan peringkat 10.

\section{HASIL DAN PEMBAHASAN}

Akun instagram dari 10 brand terkenal di dunia diantaranya:

1. Dolce and Gabanna

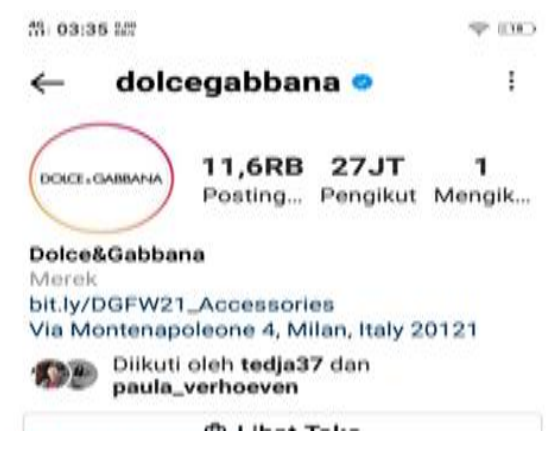

Sumber: https://www.instagram.com/dolcegabbana 
2. Gucci

3. Ralp Laurent

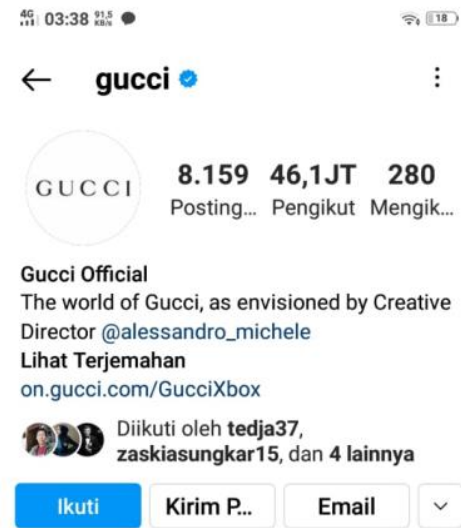

Sumber : https://www.instagram.com/gucci

\section{Gior Gior Armani}

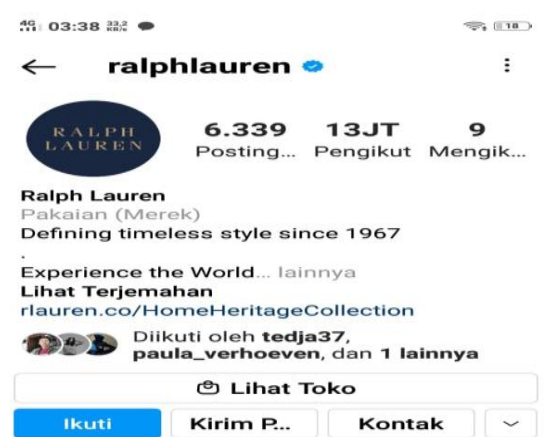

Sumber : https://www.instagram.com/ralphlauren/

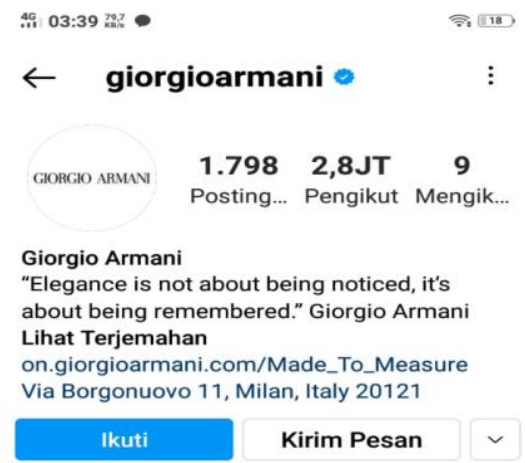

Sumber : https://www.instagram.com/giorgioarmani/

5. Yvest Saint Lauren 


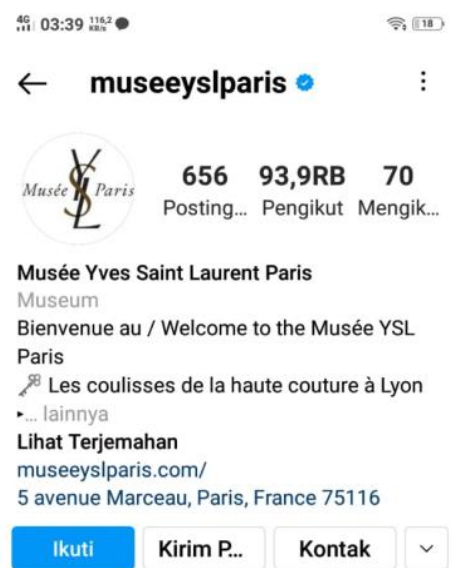

Sumber : https://www.instagram.com/museeyslparis/

6. Prada

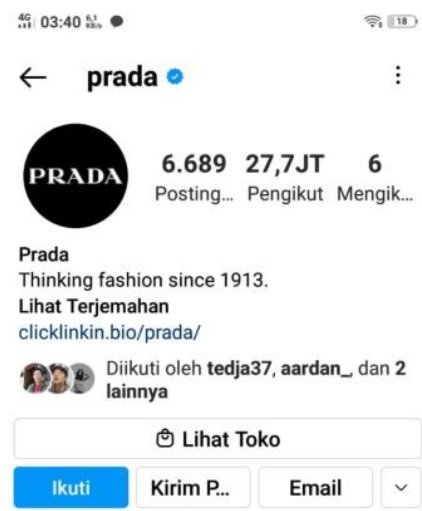

Sumber : https://www.instagram.com/prada/

7. Chanel

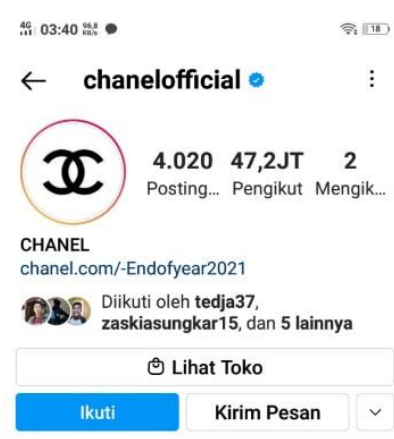

Sumber : https://www.instagram.com/chanelofficial/

8. Versace 


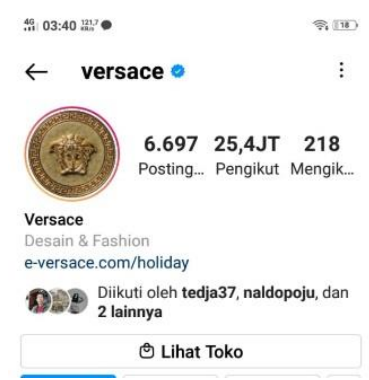

Sumber : https://www.instagram.com/versace/

\section{Christian Dior}

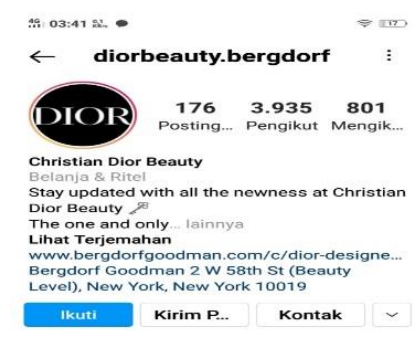

Sumber : https://www.instagram.com/dior/

10. Louis Vuitton

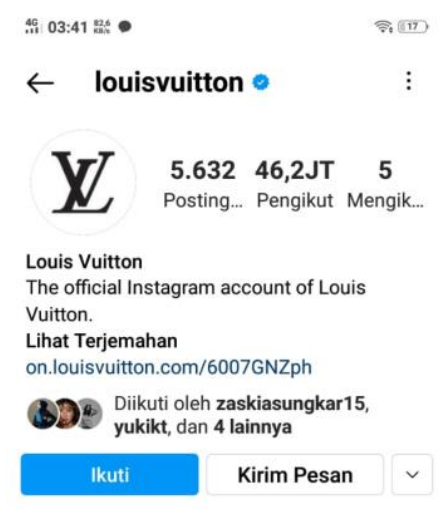

Sumber : https://www.instagram.com/louisvuitton

Dari ke 10 akun instagram top brand terkenal di dunia, peneliti menemukan nilai dari masing variabel yang ada untuk menghitung video View to Followers Ratio dari setiap akun. Pada akun instagram terdapar 6 variable diantaranya yaitu:
1. Post
2. Followers
3. Following
4. Image like
5. Image coment
6. Video view 
Dari ke 6 variabel tersebut peneliti hanya fokus menemukan 2 hasil variable yaitu:

1. Video view

2. Followers

Dari kedua variabel tersebut kemudian dianalisa sehingga menemukan nilai rata-rata dari variabel video view dan followers. Untuk menghitung rata-rata dari variabel diambil 8 postingan dari masing masing akun instagram kemudian di hitung, sehingga menemukan nilai rata rata dari setiap akun. Berikut merupakan tabel nilai rata rata dari masing akun instagram yang sudah dianalisis.

Tabel 1. Analisis nilai rata rata nilai variabel video view to follower's akun dolce and gabbana.

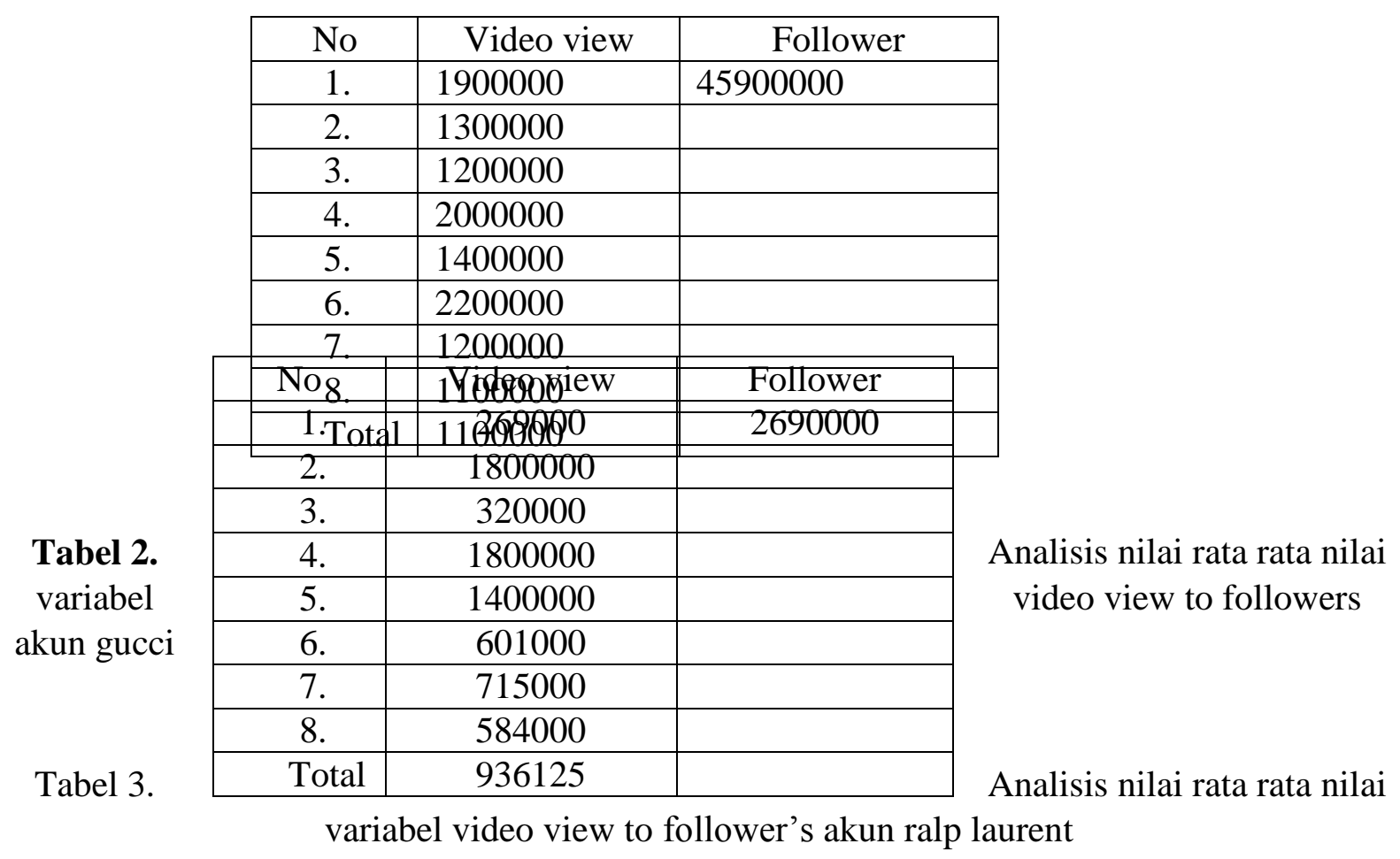




\begin{tabular}{|c|c|c|}
\hline No & Video view & Follower \\
\hline 1. & 165000 & 12900000 \\
\hline 2. & 183000 & \\
\hline 3. & 164000 & \\
\hline 4. & 147000 & \\
\hline 5. & 158000 & \\
\hline 6. & 181000 & \\
\hline 7. & 134000 & \\
\hline 8. & 134000 & \\
\hline Total & 158000 & \\
\hline
\end{tabular}

Tabel 3. Analisis nilai rata rata nilai variabel video view to follower's akun ralp laurent

\begin{tabular}{|c|l|c|}
\hline \multicolumn{1}{|l|}{ No } & \multicolumn{1}{|l|}{ Video view } & follower \\
\hline 1. & 3676 & 2700000 \\
\hline 2. & 15900 & \\
\hline 3. & 11500 & \\
\hline 4. & 14800 & \\
\hline 5. & 25800 & \\
\hline 6. & 11600 & \\
\hline 7. & 46500 & \\
\hline 8. & 49200 & \\
\hline Total & 22372 & \\
\hline
\end{tabular}

Tabel 4. Analisis nilai rata rata nilai variabel video view to follower's akun Gior Gior Armani

\begin{tabular}{|c|l|c|}
\hline No & \multicolumn{1}{|l|}{ Video view } & follower \\
\hline 1. & 2710 & 89600 \\
\hline 2. & 12200 & \\
\hline 3. & 3485 & \\
\hline 4. & 4334 & \\
\hline 5. & 4935 & \\
\hline 6. & 5827 & \\
\hline 7. & 8120 & \\
\hline
\end{tabular}




\begin{tabular}{|l|l|l|}
\hline 8. & 1550 & \\
\hline Total & 5395.125 & \\
\hline
\end{tabular}

Tabel 5. Analisis nilai rata rata nilai variabel video view to follower's akun Yvest Saint Lauren

\begin{tabular}{|c|l|c|}
\hline No & \multicolumn{1}{|l|}{ Video view } & follower \\
\hline 1. & 352000 & 27600000 \\
\hline 2. & 363000 & \\
\hline 3. & 515000 & \\
\hline 4. & 1400000 & \\
\hline 5. & 540000 & \\
\hline 6. & 407000 & \\
\hline 7. & 415000 & \\
\hline 8. & 442000 & \\
\hline Total & 554250 & \\
\hline
\end{tabular}

Tabel 6. Analisis nilai rata rata nilai variabel video view to follower's akun prada

\begin{tabular}{|c|l|c|}
\hline No & \multicolumn{1}{|l|}{ Video view } & follower \\
\hline 1. & 833000 & 46700000 \\
\hline 2. & 1000000 & \\
\hline 3. & 1700000 & \\
\hline 4. & 1000000 & \\
\hline 5. & 890000 & \\
\hline 6. & 844000 & \\
\hline 7. & 803000 & \\
\hline 8. & 1500000 & \\
\hline Total & 833000 & 46700000 \\
\hline
\end{tabular}

Tabel 7. Analisis nilai rata rata nilai variabel video view to follower's akun Chanel

\begin{tabular}{|c|l|c|}
\hline No & \multicolumn{1}{|l|}{ Video view } & follower \\
\hline 1. & 496000 & 25100000 \\
\hline 2. & 669000 & \\
\hline 3. & 813000 & \\
\hline 4. & 964000 & \\
\hline 5. & 2800000 & \\
\hline 6. & 843000 & \\
\hline 7. & 2100000 & \\
\hline 8. & 852000 & \\
\hline Total & 1192125 & \\
\hline
\end{tabular}

Tabel 8. Analisis nilai rata rata nilai variabel video view to follower's akun versace 


\begin{tabular}{|c|l|c|}
\hline No & \multicolumn{1}{|l|}{ Video view } & follower \\
\hline 1. & 414000 & 37800000 \\
\hline 2. & 441000 & \\
\hline 3. & 410000 & \\
\hline 4. & 6800000 & \\
\hline 5. & 6500000 & \\
\hline 6. & 7800000 & \\
\hline 7. & 712000 & \\
\hline 8. & 622000 & \\
\hline Total & 2962375 & \\
\hline
\end{tabular}

Tabel 9. Analisis nilai rata rata nilai variabel video view to follower's akun Christian Dior

\begin{tabular}{|c|l|c|}
\hline No & \multicolumn{1}{|l|}{ Video view } & follower \\
\hline 1. & 1200000 & 45900000 \\
\hline 2. & 1200000 & \\
\hline 3. & 1300000 & \\
\hline 4. & 1300000 & \\
\hline 5. & 1000000 & \\
\hline 6. & 2300000 & \\
\hline 7. & 1000000 & \\
\hline 8. & 988000 & \\
\hline Total & 1286000 & \\
\hline
\end{tabular}

Tabel 10. Analisis nilai rata rata nilai variabel video view to follower's akun Louis vuitton

Setelah menghitung nilai rata rata maka akan menemukan hasil akhir nilai rata rata dari video view to followers.

\begin{tabular}{|l|l|l|l|l|l|l|l|l|l|l|}
\hline $\begin{array}{l}\text { varia } \\
\text { ble }\end{array}$ & $\begin{array}{l}\text { dolce } \\
\text { dan } \\
\text { gabba } \\
\text { na }\end{array}$ & gucci & $\begin{array}{l}\text { ralp } \\
\text { lauren } \\
\text { t }\end{array}$ & $\begin{array}{l}\text { giorg } \\
\text { io } \\
\text { arma } \\
\text { ni }\end{array}$ & $\begin{array}{l}\text { yvest } \\
\text { saint } \\
\text { laure } \\
\text { nt }\end{array}$ & prada & $\begin{array}{l}\text { chane } \\
\text { l }\end{array}$ & $\begin{array}{l}\text { versac } \\
\text { e }\end{array}$ & $\begin{array}{l}\text { christi } \\
\text { an } \\
\text { dior }\end{array}$ & $\begin{array}{l}\text { louis } \\
\text { vuitto } \\
\text { n }\end{array}$ \\
\hline $\begin{array}{l}\text { video } \\
\text { view }\end{array}$ & $\begin{array}{l}5395 . \\
125\end{array}$ & $\begin{array}{l}15375 \\
00\end{array}$ & $\begin{array}{l}15800 \\
0\end{array}$ & $\begin{array}{l}2237 \\
2\end{array}$ & $\begin{array}{l}5395 \\
125\end{array}$ & $\begin{array}{l}55425 \\
0\end{array}$ & $\begin{array}{l}10712 \\
50\end{array}$ & $\begin{array}{l}11921 \\
25\end{array}$ & $\begin{array}{l}29623 \\
75\end{array}$ & $\begin{array}{l}12860 \\
00\end{array}$ \\
\hline $\begin{array}{l}\text { follo } \\
\text { wers }\end{array}$ & $\begin{array}{l}26900 \\
000\end{array}$ & $\begin{array}{l}45900 \\
000\end{array}$ & $\begin{array}{l}12900 \\
000\end{array}$ & $\begin{array}{l}2700 \\
000\end{array}$ & $\begin{array}{l}8960 \\
0\end{array}$ & $\begin{array}{l}27600 \\
000\end{array}$ & $\begin{array}{l}46700 \\
000\end{array}$ & $\begin{array}{l}25100 \\
000\end{array}$ & $\begin{array}{l}37800 \\
000\end{array}$ & $\begin{array}{l}45900 \\
000\end{array}$ \\
\hline
\end{tabular}

Tabel 11. Nilai variabel pada akun 10 brand terkenal di dunia tahun 2021 


\begin{tabular}{|c|c|c|c|c|c|c|c|c|c|c|c|}
\hline $\begin{array}{l}\text { rasi } \\
\text { o }\end{array}$ & $\begin{array}{l}\text { dolce } \\
\text { dan } \\
\text { gabb } \\
\text { ana }\end{array}$ & gucci & $\begin{array}{l}\text { ralp } \\
\text { laure } \\
\text { nt }\end{array}$ & $\begin{array}{l}\text { giorg } \\
\text { io } \\
\text { arma } \\
\text { ni }\end{array}$ & $\begin{array}{l}\text { yvest } \\
\text { saint } \\
\text { laure } \\
\text { nt }\end{array}$ & prada & $\begin{array}{l}\text { chan } \\
\text { el }\end{array}$ & $\begin{array}{l}\text { vers } \\
\text { ace }\end{array}$ & $\begin{array}{l}\text { christ } \\
\text { ian } \\
\text { dior }\end{array}$ & $\begin{array}{l}\text { louis } \\
\text { vuitt } \\
\text { on }\end{array}$ & $\begin{array}{l}\text { karas } \\
\text { terikt } \\
\text { ik }\end{array}$ \\
\hline $\begin{array}{l}\text { vid } \\
\text { eo } \\
\text { vie } \\
\text { w } \\
\text { to } \\
\text { foll } \\
\text { ow }\end{array}$ & & & & & & & & & & & \\
\hline ers & 0.000 & 0.033 & 0.012 & 0.008 & 60.21 & 0.020 & 0.022 & 0.04 & 0.078 & 0.028 & \\
\hline rati & 2005 & 4967 & 2480 & 2859 & 3448 & 0815 & 9389 & 7495 & 3697 & 0174 & TIN \\
\hline o & 62 & 32 & 62 & 26 & 66 & 22 & 72 & 02 & 09 & 29 & GGI \\
\hline
\end{tabular}

Tabel 12. Hasil perhitungan rasio akun instagram

\begin{tabular}{|c|c|c|c|c|c|c|c|c|c|c|c|}
\hline \multirow[t]{2}{*}{$\begin{array}{c}\text { perangki } \\
\text { ngan }\end{array}$} & $\begin{array}{l}\text { dolce } \\
\text { dan } \\
\text { gabb } \\
\text { ana } \\
\end{array}$ & $\begin{array}{l}\text { guc } \\
\text { ci }\end{array}$ & $\begin{array}{l}\text { ralp } \\
\text { laur } \\
\text { ent }\end{array}$ & $\begin{array}{l}\text { gior } \\
\text { gio } \\
\text { arma } \\
\text { ni }\end{array}$ & $\begin{array}{l}\text { yves } \\
\mathrm{t} \\
\text { saint } \\
\text { laur } \\
\text { ent }\end{array}$ & $\begin{array}{l}\text { pra } \\
\text { da }\end{array}$ & $\begin{array}{l}\text { cha } \\
\text { nel }\end{array}$ & $\begin{array}{l}\text { vers } \\
\text { ace }\end{array}$ & $\begin{array}{l}\text { christ } \\
\text { ian } \\
\text { dior }\end{array}$ & $\begin{array}{l}\text { louis } \\
\text { vuitt } \\
\text { on }\end{array}$ & $\begin{array}{l}\text { karasteri } \\
\text { ktik }\end{array}$ \\
\hline & 10 & 4 & 8 & 9 & 1 & 7 & 6 & 3 & 2 & 5 & \\
\hline
\end{tabular}

Tabel 13. Perangkingan hasil dari nilai rasio

Dari Tabel Nilai Rasio Akun instagram Top 10 brand terkenal di dunia Q1-2021 dapat simpulkan bahwa yvest sain Lauren mendapatkan nilai tertinggi untuk rasio Video view to followers. Sedangkan akun dolce and gabbana mendapatkan nilai terendah untuk rasio ini. Jadi, pada penelitian ini yvest saint Lauren memiliki kredibilitas performa yang lebih baik dibandingkan dengan akun brand yang lainnya.

\section{Kesimpulan}

Tujuan dari penelitian ini adalah mengetahui kredibilitas performa dari akun instagram 10 brand terkenal di dunia menggunakan video view to follower's ratio. Dapat disimpulkan bahwa:

1. Peringkat pertama diraih oleh yvest saint laurent

2. Peringkat ke dua diraih oleh christian dior

3. Peringkat ke tiga diraih oleh versace

4. Peringkat ke empaat diraih oleh gucci 
5. Peringkat ke lima diraih oleh louis vuitton

6. Peringkat ke enam diraih oleh chanel

7. Peringkat ke tujuh diraih oleh prada

8. Peringkat ke delapan diraih oleh ralp laurent

9. Peringkat ke sembilan diraih oleh giorgio armani

10. Peringkat kesepuluh diraih oleh dolce and gabbana 


\section{Daftar pustaka}

Batam, Universitas Internasional. 2020. "ANALISIS FENOMENA SOSIAL MEDIA DAN KAUM MILENIAL : STUDI KASUS TIKTOK” 1: 565-72.

Ishihara, Yemikaori Yumna Ulya, and Roswita Oktavianti. 2021. "Personal Branding Influencer Di Media Sosial TikTok.” Koneksi 5 (1): 76-82. https://doi.org/10.24912/KN.V5I1.10162.

Nurudin 2012. "Media Sosial Baru dan Munculnya Revolusi Proses Komunikasi", 551253(246), 140.

Saputera, R., dan Tamburian, D. 2019. "Pemanfaatan Media Sosial Instagram oleh Endorser dalam Membangun Citra Diri". Prologia, 2(2), 473.

https://doi.org/10.24912/pr.v2i2.3732. 